\title{
A historiografia da educação paranaense no cenário da História da Educação Brasileira:10 anos de pesquisa na Universidade Federal do Paraná $(1999-2008)^{1}$
}

\section{Historiography of Parana's education in the Brazilian Education History scenario: 10 years of research at Federal University of Paraná [Universidade Federal do Paraná] (1999-2008)}

\author{
Marcus Levy Bencostta ${ }^{2}$ \\ Diana Gonçalves Vidal ${ }^{3}$
}

\begin{abstract}
RESUMO
Este artigo trata da produção acadêmica da Linha de Pesquisa História e Historiografia da Educação do Programa de Pós Graduação em Educação da Universidade Federal do Paraná, construída em seus primeiros dez anos (1999-2008) de dedicação à formação de pesquisadores. Trata-se de um ensaio cuja cartografia bibliográfica apresenta interesse historiográfico ao analisar a relação estabelecida por esse grupo de investigadores com o cenário das trilhas percorridas pela produção nacional em História da Educação.

Palavras-Chave: História; Historiografia; Educação Brasileira.
\end{abstract}

1 Este artigo é resultado das análises apresentadas pelos autores durante conferência em comemoração aos 10 anos de existência da Linha de Pesquisa História e Historiografia da Educação do Programa de Pós-graduação em Educação da Universidade Federal do Paraná- Brasil

Professor Associado da Universidade Federal do Paraná com atuação no Programa de Pós-Graduação em Educação na mesma universidade. Coordenador do Núcleo de Estudos e Pesquisas

em História da Arquitetura Escolar (NEPHArqE) e bolsista Produtividade em Pesquisa do Conselho Nacional de Desenvolvimento Científico e Tecnológico (CNPq) - Brasil. E-mail: marcus@ufpr.br

3 Professora Livre-Docente da Universidade de São Paulo com atuação no Programa de Pós-Graduação em Educação na mesma universidade. Coordenadora do Núcleo Interdisciplinar de Estudos e Pesquisas em História da Educação (NIEPHE) e bolsista Produtividade em Pesquisa do Conselho Nacional de Desenvolvimento Científico e Tecnológico (CNPq) - Brasil. E-mail: dvidal@usp.br 


\begin{abstract}
This article concerns the academic output of the History and Historiography of Education researching field of the Post graduation program in Education of the Federal University of Paraná (Universidade Federal do Paraná), which was created in its first ten years (1999-2008) of dedication to the instruction of the researchers. It's an essay whose bibliographic cartography has a historiographic interest when analyzing the relation set by this researchers group with the scenario of the paths made by the national output in the field of Education History.

Keywords: History; Historiography; Brazilian Education.
\end{abstract}

\title{
Um campo de pesquisa em construção
}

É possível dizer que, mais intensamente nos últimos cinco anos, temos assistido na nossa área de atuação um vivo interesse por refletir sobre a produção do campo. No período em tela, destacam-se o Seminário "A produção da pesquisa em história da educação no Brasil" " , realizado em 2004, no Rio de Janeiro, sob o patrocínio do GT 2 da ANPEd; e a mesa-redonda, promovida pela Sociedade Brasileira de História da Educação, no IV Congresso Brasileiro de História da Educação, ocorrido em Goiânia, em 2006, intitulada "Historiografia da educação: para além dos balanços".

No entanto, a despeito da repercussão destes dois fóruns, o esforço em repensar o campo de pesquisa lhes era anterior. E pode ser dividido em duas vertentes. A primeira envia às iniciativas individuais, a segunda remete às encomendas de grupos de pesquisa. No primeiro caso, poderíamos citar os vários trabalhos de Marta Carvalho (1989; 1995; 2000), Dermeval Saviani (1983; 2005), Carlos Monarcha (1993; 1996; 2007), Clarice Nunes (1995; 1996) e Mirian Warde (1984; 1990; 1998), bem como as teses de Luiz Carlos Barreira (1995), Zaia Brandão (1992) e a dissertação de Bruno Bontempi Jr. (1995), dentre outros.

Para as análises encomendadas, além das elaboradas para os fóruns citados anteriormente, encontram-se os artigos de Clarice Nunes e Marta Carvalho (1991), Clarice Nunes (1991) e Denice Catani e Luciano Faria Filho (2002), elaborados a pedido do GT 2 da ANPEd; os textos de Clarice Nunes (1998), Claudia Alves (1998), Cynthia Greive Veiga e Joaquim Pintassilgo (2000), Libânia Xavier (2001) e Marta Araújo (2006), produzidos como falas de encerra-

4 As falas desse Seminário resultaram na obra organizada por Gondra (2005). 
mentos de Congressos Brasileiros e Luso-brasileiros de História da Educação; o artigo de Luciano Mendes de Faria Filho e Diana Vidal (2003), escrito a pedido da Revista Brasileira de História; os textos de Dermeval Saviani, José Luis Sanfelice e José Claudinei Lombardi (1998; 2001), elaborados por solicitação do Grupo de Pesquisa HISTEDBR.

A relação cresce se consideramos os trabalhos apresentados em mesasredondas de Congressos, construídos não a partir de uma encomenda explícita de balanço, mas como resultado da intenção de fornecer um olhar geral sobre o campo ou sobre temáticas a ele associadas, como os textos sobre revistas educacionais elaborados por Maria Helena Câmara Bastos (2006), José Luis Sanfelice (2006) e Denice Catani e Cynthia P. de Sousa (2001); sobre etnia por Cynthia Greive Veiga (2006) ou sobre gênero por Diana Vidal (2006), dentre outros.

Esse cenário traçado em largas pinceladas e sem a pretensão de ser exaustivo, nos incita a indagar que vontade memória (e de esquecimento) ele testemunha. É claro que não podemos afirmar que as avaliações efetuadas pelos vários autores conduzam a interpretações consoantes sobre a produção historiográfica em educação nacional. Ao contrário, a despeito de diagnósticos por vezes semelhantes, essa bibliografia quando confrontada apresenta tensões que se revelam de diferentes maneiras, como, por exemplo, o recurso a distintas bases de informação. Há autores que preferem analisar teses e dissertações, há outros que se debruçam sobre os textos completos publicados nos Anais dos Congressos, ainda há aqueles que escolhem os artigos saídos em revistas ou coletâneas. Cada uma dessas opções é devidamente explicitada e justificada. E para além das constantes precauções sobre o volume da documentação visitada, essas escolhas indicam modos como os pesquisadores percebem o funcionamento do campo e conferem importância (e visibilidade) aos produtos.

Não vai aqui uma crítica à operação de selecionar e recortar. Todos nós sabemos que na pesquisa científica é sempre necessário delimitar o universo de estudo. Mas também sabemos que a delimitação implica em uma compreensão do próprio objeto. A pergunta, portanto é o que temos valorizado como significativo no panorama da historiografia educacional brasileira? O fato dos vários textos tomarem bases de dados distintas não sinaliza para uma dispersão do que temos considerado como relevante na socialização da pesquisa em História da Educação?

Outra maneira de percorrer o debate é perceber que o esforço em repensar o campo tem ênfases históricas distintas.

Num primeiro momento, nos anos 1980 e inícios dos 1990, ele é caracterizado pela denúncia da pregnância, na escrita da história da educação, do padrão narrativo de Fernando de Azevedo (como, por exemplo, nos trabalhos 
de Marta Carvalho e Zaia Brandão, citados) ou da interpretação dos pioneiros (como no estudo de Saviani, 1983).

Já em meados da década de 1990, a discussão historiográfica se volta para uma análise mais quantitativa da produção, revelada nos vários balanços que tomam os Congressos e os programas de Pós-Graduação como base documental. Recentemente, são os artigos publicados em revistas e coletâneas os alvos da construção de uma inteligibilidade ao campo.

Por certo, essas diferentes investidas revelam a própria história da disciplina. Os primeiros escritos estão associados ao nascimento dos Programas de Pós-Graduação em Educação no país e à constituição da História da Educação como uma linha de pesquisa autônoma. Representativa desse momento é a criação do GT História da Educação da ANPEd (1984) e do grupo HISTEDBR (1986). Os novos ares que respiravam no país, fruto do momento de abertura política, assim como do declínio de paradigmas que dependiam do econômico para a construção de interpretações, favoreceram a acolhida de movimentos revisionistas. Por outro lado, a paulatina autonomização da História da Educação da sua parceria com a Filosofia da Educação requeria a refundação das tradições.

Em meados da década de 1990, o fortalecimento da Pós-Graduação no país evidenciava-se não apenas no crescente volume dos trabalhos defendidos como na abertura de programas nas diversas universidades brasileiras. É nesse período que surgem e se multiplicam os fóruns de socialização da pesquisa acadêmica, como os vários congressos Ibero-americanos (o primeiro é de 1992) e Lusobrasileiros de História da Educação (o primeiro é de 1996). E se constituem a Associação Sul-rio-grandense de Pesquisadores em História da Educação/ ASPHE (1996) e a Sociedade Brasileira de História da Educação/ SBHE (1999). Sobressaltados pelo acúmulo da produção decorrente da expansão dos Programas, os pesquisadores procuraram avaliar quantitativamente esse crescimento. Reafirmavam assim o entendimento da História da Educação como um campo em expansão.

Recentemente, o foco das análises tem se deslocado para as revistas educacionais e para as coletâneas. A virada evidencia dois novos investimentos do campo. O primeiro foi a constituição de periódicos específicos para a difusão da investigação em História da Educação. São eles: a revista História da Educação da ASPHE (fundada em 1997), a Histedbr on-line (fundada em 2000), a Revista Brasileira de História da Educação da SBHE (fundada em 2001) e a Cadernos de História da Educação (fundada em 2002). O interesse pelos periódicos veio na dupla perspectiva de dar visibilidade às pesquisas realizadas no campo e de responder às demandas das agências de fomento. Foi pela crescente importância que as revistas adquiriram no âmbito das avaliações CAPES que elas assumiram lugar de destaque nas interpretações sobre 
a configuração do campo. Não deixa de ser instigante, no entanto, indagar sobre os efeitos dessa política, que tem repercutido em uma espécie de "confinamento" da produção historiográfica em educação brasileira nos veículos especializados. Por um lado, sem dúvida, ampliamos nosso diálogo com o campo. Por outro, ao deixarmos de ocupar espaço nos periódicos do setor de Educação, não promovemos certa invisibilidade para as nossas pesquisas na arena educacional?

O estreitamento das relações entre os historiadores da educação, resultado da participação em Congressos, tem suscitado a realização de ações conjuntas, superando de maneira mais ampla a circunscrição regional da produção. Assim, como investida do campo têm aparecido coletâneas temáticas que procuram superar a dispersão dos trabalhos, reunindo investigadores dos vários estados brasileiros. Só para citar dois exemplos, temos o livro Grupos escolares, cultura escolar primária da infância no Brasil (1893-1971), organizado por Diana Vidal (2006), e As escolas normais do Brasil - do Império à República, por Anamaria Freitas, José Carlos Araujo e Antonio de Pádua Lopes (2008). Elas visam, dentre outros objetivos, promover a propalada comparação: preocupação reiterada nos discursos da última década. E evidenciam que, no panorama atual da disciplina, a prática de identificar a história da educação do sudeste à história nacional já não encontra mais legitimidade. Voltaremos a este ponto mais adiante, discorrendo sobre os efeitos dessa nova abordagem.

Uma terceira maneira de percorrer o debate historiográfico é tomar as diferentes aproximações teóricas que conduzem os pesquisadores a olhar a produção histórica em educação brasileira e construir sobre ela inteligibilidades. Essa nos parece a seara mais indistinta na qual nos movemos. Indistinta não porque não tenhamos clareza das vertentes teóricas a que nos filiamos, mas porque os textos sobre a produção brasileira pouco têm investido na explicitação dessas escolhas. Não deixa de ser interessante problematizar essa ausência.

Por um lado, não é verdade que os vários balanços não tenham sinalizado para a necessidade de identificar as escolhas teóricas. Mas ela emerge nas escritas como um investimento ainda a ser efetuado. As dificuldades provêm das mais diferentes razões. $\mathrm{O}$ grande volume da produção e a falta de tempo para análise sistemática dos dados são as mais frequentes.

Por outro lado, viceja entre nós certo consenso de que, grosso modo, a nossa produção historiográfica oscila entre um apego ao marxismo ou uma adesão à Nova História Cultural. Esse quadro geral traz mais problemas de entendimento dos contornos de nossas pesquisas que soluções. Inicialmente, reúne sob o mesmo "rótulo" perspectivas de análises por vezes muito diversas. Só para tomar o caso do marxismo, não é a mesma coisa falar de Marx, Althusser 
ou E.P. Thompson. Aliás, Thompson é um bom exemplo da indefinição dessas fronteiras. Há autores que o situam nas hostes do marxismo, enquanto outros o veem como um historiador da cultura (historiador cultural?).

Em segundo lugar, esse quadro coloca à sombra autores e abordagens que têm largo assento nas nossas disciplinas-mães e, portanto, é de supor que tenham entrada na própria história da educação. Apenas dois exemplos, citaríamos a importância de Carlos Ginzburg e da micro-história na renovação das análises historiográficas no Brasil, e de Michel Foucault na construção de inteligibilidades em todos os campos de investigação educacional. De forma impressionista, sabemos que os dois autores participam frequentemente de nossas leituras e constituem-se em relevantes referências de interpretação. Mas desaparecem no diagnóstico bipolar que, por vezes, realizamos das vertentes teóricas de nosso campo.

As escusas que utilizamos para fugir de um estudo mais sistemático de nossos empréstimos intelectuais indiciam algumas características do campo. A primeira delas é a que nos leva a tocar profundamente nas divisões existentes entre os grupos de pesquisadores. A criação de fóruns de congraçamento, como os Congressos, apesar de terem auxiliado em muito a aproximar os grupos ainda não foram suficientes para dissipar as tensões. E nem sabemos se serão capazes, posto que o funcionamento de todo campo acadêmico se processa no jogo de lutas de poder. Nesse sentido, temos confundido disputas teóricas com disputas políticas. Também não sabemos se é possível distinguir tão positivamente as duas coisas. Mas pensamos que seria o caso de investirmos com maior dedicação em constituir fóruns de debates acadêmicos que acolham de maneira mais ampla a diversidade e se permitam contemplar abertamente o dissenso. Afinal, nem sempre precisamos estar de acordo para continuar a trabalhar conjuntamente.

A segunda razão é que a produção historiográfica educacional brasileira em boa parte viceja no ecletismo das teorias, recompondo quadros de entendimento do nacional referenciados por literatura estrangeira. Não diríamos, como alguns autores, que estamos presos a um cenário de colonização do pensamento. Ao contrário, acreditamos que o ecletismo de nossa produção espelha os limites da incorporação da bibliografia internacional, constituída por trajetórias sócio-históricas específicas e na resposta a problemas de pesquisas singulares de cada uma das realidades históricas tomadas. Nesse sentido, parece-nos, no amadurecimento das fusões estabelecidas e no enfrentamento ao desafio de teorizar "em português" caminharemos para o desejável movimento de elaboração de referenciais, construídos no diálogo com autores de outros países, sim, mas assentados em problemáticas que nos são específicas. 
Evidentemente estas três perspectivas apontadas não são as únicas. Mas passemos a discutir a experiência da Linha de Pesquisa História e Historiografia da Educação, alvo maior de nossas atenções nesse ensaio.

\section{Registros dos passos iniciais de um projeto...}

Em 1998, após dois anos de discussão nas câmaras da universidade, o Programa de Pós-Graduação em Educação da Universidade Federal do Paraná tem aprovada a reformulação de sua proposta para um novo formato. Com um cenário de mudanças delicadas, a professora Serlei Maria Fischer Ranzi, juntamente aos professores Carlos Eduardo Vieira e Marcus Levy Albino Bencostta, encampam a missão de fundar no Programa uma linha de pesquisa que privilegiasse os estudos em História da Educação. Naquele momento de constituição, esse primeiro grupo de pioneiros foi responsável pelo convite à professora Maria Cecília Marins de Oliveira para compor seu quadro permanente, assim como, à professora Arlene Renk da Universidade do Oeste de Santa Catarina (UNOESC) e ao professor Kazumi Munakata da Pontifícia Universidade Católica de São Paulo (PUC-SP) na qualidade de colaboradores. ${ }^{5}$

Assim foi que, em 1999, ${ }^{6}$ se configurou o quadro original que daria início às atividades da Linha então denominada História e Historiografia da Educação.

A desejada revitalização do Programa de Pós-graduação em Educação da UFPR se deu com a vinda de novos pesquisadores, quando entrou em cena o desafio de se estruturar o primeiro doutorado em Educação do estado do Paraná, tarefa difícil de executar, mas que a Linha de Pesquisa não deixou de ter uma atuação solidária às demais no objetivo de consolidar sua atuação no cenário nacional. Assim 2001, ano que marcou o credenciamento pela CAPES do nível de doutorado desse Programa, destaca-se também pela chegada de duas outras

5 Não foram consideradas as produções dos professores colaboradores por compreendermos que estas são de pertencimento às universidades onde atuam com maior dedicação.

6 Por feliz coincidência esse foi o mesmo ano da fundação da Sociedade Brasileira de História da Educação (SBHE). É interessante recordar que no ano de 1999 estiveram presentes no Palace Hotel de Caxambu (Minas Gerais), como sócios que assinaram a ata de fundação da SBHE, os professores Marcus Levy Albino Bencostta e Carlos Eduardo Vieira, representantes, naquele momento, do grupo de pesquisadores em História da Educação da Universidade Federal do Paraná. 
importantes vinculações, tratavam-se dos professores Marcus Aurélio Taborda de Oliveira e Vera Regina Beltrão Marques.

Com a nova proposta aprovada pela CAPES, a Linha passou a ser designada Instituições, Intelectuais e Cultura Escolar por serem esses os eixos que melhor identificavam as pesquisas de seus professores. Entretanto, tal denominação permaneceu até a reforma curricular de 2004, quando retorna o título original e que segue até hoje, qual seja: História e Historiografia da Educação.

No ano seguinte ao da criação do doutorado, em 2002, foi a vez de Gilberto de Castro e Liane Maria Bertucci se juntarem ao conjunto de docentes permanentes. A Linha esperou mais dois anos, até 2004, para incorporar ao seu grupo de investigadores a professora Nádia Gaiofatto Gonçalves e, em 2005, a recém doutora Gizele de Souza. Finalmente no ano em que completaram dez anos, ocorreu o credenciamento de Dulce Regina Baggio Osinski. ${ }^{7}$

Na experiência construída nos últimos dez anos, esses pesquisadores foram responsáveis pela formação de 51 alunos de Iniciação Científica, 48 titulações de mestrado e 06 de doutorado, sendo que ainda estavam em andamento no ano de 2008: 12 orientações de alunos de iniciação científica, 14 pesquisas de mestrado e 17 de doutorado, o que demonstra o seu investimento prospectivo na formação de pesquisadores em História da Educação.

Quanto ao trabalho de criação intelectual no campo do conhecimento da História da Educação que os professores e seus orientandos de mestrado e doutorado conseguiram produzir no espaço de tempo de chegada e permanência no grupo de pesquisadores é representada por 245 trabalhos completos (140 de docentes e 105 de discentes) divulgados em anais de eventos nacionais e internacionais, 65 artigos publicados (51 de docentes e 14 de discentes) em diversos periódicos acadêmicos respeitados pela área e outras afins, 75 capítulos de livros (45 de docentes e 30 de discentes), edição de 10 coletâneas (todas de docentes) e publicação de 18 livros integrais (08 de docentes e 10 de discentes).

Para esse inventário não foi inserida a produção dos alunos de iniciação científica, pois se trata na sua maioria de resumos em eventos, onde foi possível sua participação, mas quando estes possuem trabalhos completos, os mesmos estão vinculados em coautoria com seus orientadores, computados, portanto, no desempenho dos professores.

7 Dentre os professores que tiveram uma importante participação temporária estão os colegas: Gilberto de Castro (2002-2005) e Maria Cecília Marins de Oliveira (1999-2003), que atualmente encontram-se vinculados a outras linhas do Programa de Pós-Graduação em Educação da UFPR. 


\section{Metodologia do Estudo}

Para construir uma metodologia que avaliasse as peculiaridades dessa historiografia foi necessária a consulta a documentos gerais, como os relatórios anuais enviados à Comissão de Avaliação da CAPES, os currículos registrados na plataforma Lattes do CNPq dos alunos e professores, além de documentos particulares, como as teses e dissertações defendidas na Linha, trabalhos completos de congressos, livros, artigos e capítulos de livros, todos de autoria e/ou coautoria dos pesquisadores.

De modo mais geral, o esforço producente do conjunto da criação intelectual foi responsável pela construção de tendências no cenário paranaense que se somam aos esforços da historiografia educacional brasileira. Cabe ainda destacar o incremento dessa iniciativa com a constituição de núcleos e grupos de pesquisa no interior de suas atividades, coordenadas por diferentes docentes como forma de estimular a socialização de resultados de pesquisas e aprofundamento de sua produção de modo articulado. Até o momento, a Linha abriga o grupo de pesquisa Currículo e educação do corpo: história do currículo da instrução pública primária no Paraná (1882-1926), o de História Intelectual e História da Educação, o Núcleo de Estudos e Pesquisas em Infância e Educação Infantil (NEPIE), e o mais recente dentre eles, o Núcleo de Estudos e Pesquisas em História da Arquitetura Escolar (NEPHArqE). Além destes espaços, contam com o diretório do CNPq que unifica o cerne da sua produção intitulado: História da Educação: Instituições, Intelectuais e Culturas Escolares no Paraná (Século XX). Contam ainda com o Centro de Documentação e Pesquisa em História da Educação - CDPHE, fundado por decisão coletiva dos professores, com o objetivo, dentre vários, de reunir e disponibilizar para consulta a produção acadêmica do corpo docente e discente, organizar fontes e pesquisas referentes à História da Educação do Estado do Paraná.

O esforço de construção desse mapa resultou em interessantes indicadores de avaliação, aos quais a seguir nos deteremos com mais vagar e dedicação. Focaremos nossa lente em quatro aspectos metodológicos que interagem entre si e que facilitam a compreensão das veredas percorridas por esse grupo. São eles: I. A evolução da produção; II. A natureza da produção; III. As temáticas; IV. Os períodos históricos.

O número de produtos relacionados à produção do conhecimento (Tabela 1) foi marcado por um crescimento regular. Quando os dados apontam que o grupo atuante nos anos de 2006 e 2007 foi responsável por 31,2\% de toda a produção no período, não devemos esquecer o fator da proporcionalidade presente nos 
anos anteriores, a partir da qual podemos interpretar que o esforço foi significativo naqueles anos em que o número de pesquisadores fora inferior, especialmente nos dois primeiros anos de existência da Linha (1999-2000).

TABELA 1-EVOLUÇÃO DA PRODUÇÃO DO CONHECIMENTO EM HISTÓRIA DA EDUCAÇÃO

\begin{tabular}{c|c|c}
\hline Ano & Quantidade & \% \\
\hline 1999 & 23 & 4,9 \\
\hline 2000 & 23 & 4,9 \\
\hline 2001 & 30 & 6,4 \\
\hline 2002 & 30 & 6,4 \\
\hline 2003 & 41 & 8,7 \\
\hline 2004 & 70 & 14,9 \\
\hline 2005 & 57 & 12,2 \\
\hline 2006 & 71 & 16,0 \\
\hline 2007 & 71 & 15,2 \\
\hline 2008 & 51 & 10,9 \\
\hline Total & 467 & \\
\hline
\end{tabular}

A incidência de trabalhos completos apresentados em Congressos (Tabela 2) responde por um número expressivo de toda a produção. Sabemos que, circunstancialmente, as agências de financiamento à pesquisa e/ou aquela responsável pela avaliação dos programas de pós-graduação estabeleceram, até bem pouco tempo, uma política de incentivo que valorizava a participação dos pesquisadores em congressos que resultassem publicações de trabalhos completos em formato impresso ou digital. Também é amplamente conhecida a dificuldade dos pós-graduandos publicarem os resultados de suas pesquisas em periódicos e livros, não lhes restando muitas alternativas senão os providenciais congressos promovidos pelas sociedades científicas, nacionais e internacionais, os quais, muitas vezes, se traduzem na única oportunidade viável para divulgação de suas investigações. 
TABELA 2 - A NATUREZA DA PRODUÇÃO DO CONHECIMENTO EM HISTÓRIA DA EDUCAÇÃO

\begin{tabular}{l|c|c}
\hline Produto & Quantidade & $\mathbf{\%}$ \\
\hline Trabalhos completos em Anais & 245 & 52,4 \\
\hline Capítulos de livros & 75 & 16,0 \\
\hline Artigos & 65 & 13,9 \\
\hline Dissertações & 48 & 10,2 \\
\hline Autoria de Livros & 18 & 3,8 \\
\hline Organização de Coletâneas & 10 & 2,1 \\
\hline Teses & 06 & 1,2 \\
\hline Total & 467 & \\
\hline
\end{tabular}

Observando a somatória dos demais produtos bibliográficos (livros, coletâneas, capítulos de livros e artigos), que correspondem a 36\% da natureza da produção, podemos apreender que a distância estabelecida com os trabalhos completos não deixa de confirmar a ênfase nesse tipo de produto.

Ao observarmos a Tabela 3 , notamos que os produtos identificados com os temas da História dos Intelectuais e das Ideias Pedagógicas; História das Disciplinas e Métodos Escolares representam um pouco mais que 1/4 de toda a produção da Linha $(26,4 \%)$. Isso se deve não só ao peso da participação nos tipos de produtos privilegiados, mas também a uma maior produtividade dos pesquisadores envolvidos em tais temas. Essa também pode ser uma parte da explicação para os produtos identificados com os temas: História da Educação, Medicina e Saúde; Fontes e Metodologia em História da Educação; História da Educação e Corporalidade, que aumentam o prestígio de suas investigações no interior da Linha, tornando-se responsável por $22,4 \%$ da sua produção total. 
BENCOSTTA, M. L.; VIDAL, D. G. A historiografia da educação paranaense...

TABELA 3 - OS TEMAS EXAMINADOS

\begin{tabular}{|c|c|c|}
\hline Temas & Quant. & $\%$ \\
\hline História dos Intelectuais e das Ideias Pedagógicas & 70 & 15,3 \\
\hline História das Disciplinas e Métodos Escolares & 51 & 11,1 \\
\hline História da Educação, Medicina e Saúde & 39 & 8,5 \\
\hline Fontes e Metodologia em História da Educação & 33 & 7,2 \\
\hline História da Educação e Corporalidade & 31 & 6,7 \\
\hline História das Instituições de Ensino Secundário & 27 & 5,9 \\
\hline História da Educação e Estudos de Gênero & 22 & 4,8 \\
\hline Culturas e Saberes Escolares & 21 & 4,5 \\
\hline História da Legislação e Organização do Sistema Escolar & 21 & 4,5 \\
\hline História da Arquitetura Escolar & 20 & 4,3 \\
\hline História da Profissão Docente & 19 & 4,1 \\
\hline História da Educação e Trabalho & 16 & 3,5 \\
\hline História das Instituições de Ensino Primário & 16 & 3,5 \\
\hline História da Educação Infantil & 13 & 2,8 \\
\hline História da Educação e Imigração & 12 & 2,6 \\
\hline História das Instituições de Ensino Superior & 11 & 2,4 \\
\hline História da Educação e Imprensa: professores /alunos & 10 & 2,1 \\
\hline Historiografia da Educação & 9 & 1,9 \\
\hline História dos Livros e Práticas de Leitura & 8 & 1,7 \\
\hline História do Livro Didático & 4 & 0,8 \\
\hline Arquivos Escolares & 3 & 0,6 \\
\hline História da Educação, memórias, biografias, histórias de vida & 1 & 0,2 \\
\hline Total & 457 & $100 \%$ \\
\hline
\end{tabular}

* As coletâneas organizadas pelos docentes, em um total de 10 produtos, não foram inseridas nos cálculos dessa tabela por entendermos, nesse caso, a dificuldade em definir uma única temática dentre as várias possibilidades presentes em cada uma das obras. 
Os demais temas que participam com $50,2 \%$ das pesquisas levam-nos a pensar que, por um lado, os dados esclarecem uma distribuição assimétrica diante do número de produtos qualificados como um claro resultado das diferentes variáveis que os pesquisadores colocam frente às suas opções para a realização de suas análises, por outro, não podemos desconsiderar serem alguns desses temas de interesse mais recente na história da Linha.

É bastante instigante observar que no conjunto das histórias das instituições o ensino secundário apresente um interesse maior de investigação do que o ensino primário, para não mencionar o ensino superior, o que parece ser uma preocupação diferenciada se comparada com o cenário da historiografia nacional, que tem se voltado na última década a entender e explicar melhor a história da escola primária republicana no século XX. Outra questão que nos parece do mesmo modo interessante é o caráter revisionista das pesquisas sobre História da Legislação e Organização do Sistema Escolar quando comparada ao modo como eram investigados esses temas décadas atrás, quando as interpretações sobre as práticas não eram um exercício necessário.

De fato, o ensino primário tem emergido nos vários balanços como o investimento central da pesquisa em História da Educação. No entanto, parece-nos que todo o Grupo I e um contingente importante do Grupo II se destacam dos contornos da produção brasileira, indicando a especificidade do corpo docente ligado à Linha. Nesse sentido, fica como questão acompanhar as séries históricas da constituição dos temas, de maneira a reconhecer, ou não, nelas o ingresso dos professores no Programa.

A nós parece que a criação de Grupos e Núcleos, além do CDPHE, sinaliza para o investimento do corpo docente em constituir esse distintivo da produção local na identidade de uma Linha Pesquisa, superando a ação e o interesse individual dos professores e transformando-os em áreas de investigação carreadas por outros docentes. Interpretamos essa perspectiva como muito profícua, na medida em que visa a sobrepujar o circunstancial dos focos de pesquisa e permitir o acúmulo do trabalho empírico e a sistematização conceitual necessária ao fortalecimento desses temas reconfigurados em objetos de investigação de largo espectro.

Outro dado a se observar são os estudos centrados na relação história da educação e imigração. Apesar da produção da Linha ser fortemente marcada por temas da história regional, onde o Paraná foi contexto de $52 \%$ das pesquisas realizadas e, considerando que o número de instituições educacionais mantidas por grupos de imigrantes de diferentes etnias foi consideravelmente relevante para a história da educação no Estado, ainda não foi suficiente para esse tema se tornar uma tônica que tenha marcado a produção da Linha. 
Quanto à configuração na escolha de recortes temporais (Tabela 4), a Linha prezou, desde o início, manter atenção cuidadosa para que suas escolhas não fossem imediatamente identificadas com as opções que a história política privilegia (cf. "II Reinado"; "Primeira República"; "Revolução de 1930"; "Ditadura Vargas"; "Estado Novo"; "Anos JK"; etc.). Quando isso se deu, o exemplo do período da ditadura militar é bastante elucidativo, a postura adotada derivou diretamente das relações intrínsecas que seus objetos possuíam com os palcos da história política e os da história da educação.

TABELA 4 - PERÍODOS HISTÓRICOS PESQUISADOS ${ }^{8}$

\begin{tabular}{|c|c|c|}
\hline Período & Quant. & $\%$ \\
\hline O distante e silencioso Setecentos $(1700-1810) * *$ & 08 & 1,75 \\
\hline $\begin{array}{l}\text { Século XIX } \\
\text { Apenas uma metade visitada (1850-1889) }\end{array}$ & 43 & 9,40 \\
\hline $\begin{array}{l}\text { Século XX } \\
\text { Os quarentas gloriosos (1900-1939) } \\
\text { Nem tudo era "bossa" (1940-1963) } \\
\text { "Tempos de adesões e resistências" (1964-1984) }\end{array}$ & $\begin{array}{c}151 \\
61 \\
54\end{array}$ & $\begin{array}{l}33,04 \\
13,34 \\
11,81\end{array}$ \\
\hline $\begin{array}{l}\text { Século XX - XXI } \\
\text { Discussões teóricas sobre a pesquisa em } \\
\text { História da Educação e o Tempo Presente (1985-2008) }\end{array}$ & 140 & 30,63 \\
\hline Total & 457 & 100 \\
\hline
\end{tabular}

* As coletâneas organizadas pelos docentes, em um total de 10 produtos, não foram inseridas nos cálculos dessa tabela por entendermos, nesse caso, a dificuldade em definir um único período histórico dentre as várias possibilidades presentes em cada uma das obras.

** A decisão por inserir o primeiro decênio do Oitocentos no século XVII é por se tratar de uma única pesquisa que tem seu recorte prolongado até 1810 .

É notória e factível a preferência dos olhares para o século XX, diríamos até mais, privilegiou-se "Os quarentas gloriosos" (1900-1939) como o período que mais os chamou à atenção, sendo a transição do século XIX para o século

8 Os títulos atribuídos aos diferentes períodos analisados apresentam apropriações gerais da historiografia, utilizados, aqui, substancialmente como recursos estilísticos que procuram identificar o tempo histórico com realidades, experiências e fenômenos a ele relacionado. 
XX e a década de 1910, disparadamente a preferida dos pesquisadores com 95 produtos bibliográficos.

Algumas questões se destacam com a interpretação desses dados. Uma é a aparente conformidade dos períodos pesquisados à tônica geral dos trabalhos de campo. Aparente porque se encontra uma grande concentração de estudos entre os anos de 1900 e 1939 e porque há um escasso investimento sobre a época colonial.

Não é difícil imaginar a instigação que as quatro primeiras décadas do Novecentos provocam ao debate historiográfico, motivo pelo qual esta é uma tendência nacional. Internamente concorre de modo equilibrado, a predileção pelos períodos na fase "Nem tudo era Bossa" (1940-1963), e "Tempo de adesões e resistências" (1964-1984), termo emprestado da tese de Marcus Taborda (OLIVEIRA, 2001).

Dessa maneira, confirmamos por uma série de fatores que passam também pelas condições dos acervos e arquivos, o século XX foi aquele que a Linha mais produziu, com $58 \%$ do total dos períodos históricos elencados. Contudo, identificamos aqui outro aspecto distintivo desta produção. $\mathrm{Na}$ verdade, pelas estatísticas apresentadas, há um forte equilíbrio entre a concentração de estudos sobre os últimos 20 anos (1985-2008) e o interregno dos "quarenta gloriosos".

O período "O distante e silencioso Setecentos" foi de fato aquele que menos a Linha arriscou-se a percorrer. Se houve alguma experiência, ela é resultado dos trabalhos sobre a história da medicina e das artes de cura empreendidos pela pesquisadora Vera Regina Beltrão Marques, cujo empenho solitário e qualitativo de embrenhar-se naquele século nos leva a entender que ainda falta um interesse maior em investir em trabalhos com fontes sobre os "tempos jesuíticos e pombalinos", e auscultar melhor os ruídos dos fenômenos educacionais do instigante Setecentos.

O seu vizinho e um pouco mais barulhento, século XIX, em "Apenas uma metade visitada" (1850-1889), não deixou de ser percebido como uma opção de recorte temporal bastante viável. Entretanto, o centro dessa atenção ficou completamente reunido na sua segunda metade. A despeito da tendência da recusa à adoção de uma periodização marcada por formatos positivistas ou presa à história política e administrativa, não deixa de ser instigante perguntar se a ausência dos primeiros 50 anos do Oitocentos não se refere à constituição territorial do Paraná. Afinal, foi apenas em 1853 que a província se separou de São Paulo. Possivelmente, a escassa documentação no Arquivo Público do Estado do Paraná referente à primeira metade do Oitocentos avalize a falta de investigações sobre o período. A constatação coloca como problema o que consideramos por história regional e 
como constituímos retroativamente os contornos dos nossos objetos. Nessa medida - e aqui fazemos um jogo de palavras -, seria possível uma história colonial do Paraná? Em outros termos, não temos discutido pouco sobre como se constituem as imbricadas e tensas relações entre os dois pilares da história: o espaço e o tempo?

Finalizando esse roteiro interpretativo acerca do exame da periodização, sobressaíram iniciativas que levantaram questões a respeito do ofício da pesquisa em História da Educação na década final do século XX e nos primeiros anos do XXI. Em "Discussões teóricas sobre a pesquisa em História da Educação e o Tempo Presente (1985-2008)", seus produtos tomaram como objeto de discussão, a prática, o aprimoramento e a valorização de diferentes debates que destacaram, dentre outros temas, a importância das fontes no dia a dia da pesquisa, métodos de análises e ensino, assim como as contribuições teóricas de importantes interlocutores para os estudos em História da Educação. ${ }^{9}$ Distinguem-se também, nesse grupo, produtos que inserem seus objetos em um tempo presente ou imediato, contudo, a Linha reconhece a necessidade de um maior aprofundamento nos aportes teóricos dessa preferência para melhor compreender sua contribuição aos estudos do tempo presente em nosso campo de pesquisa.

\section{Considerações finais: desafios atuais para o campo da História da Educação.}

Constatamos neste ensaio que o foco da produção da Linha de Pesquisa em análise centra-se na perscrutação da realidade educacional paranaense, sem deixar, contudo, que se perca um vínculo com as problemáticas nacionais. Traçando uma relação com a realidade nacional, dentre os desafios a serem enfrentados atualmente, talvez a territorialização de objetos seja um dos primeiros. Se por um lado, ao recusarmos estender à história da educação brasileira a interpretação histórica restrita à região sudeste, enfatizamos a importância da história comparada. Por outro, ao destacar a relevância da comparação, não reforçamos as fronteiras geográficas e administrativas dos atuais Estados, desconhecendo a constituição histórica dos territórios e, mesmo, esquecendo que mais que comparadas, nossas histórias são conectadas? Em que medidas as fronteiras

9 Inseridos nesse tempo encontram-se ainda os livros didáticos de autoria de professores e/ou alunos da Linha. 
geográficas não têm emergido em nossos trabalhos atuais como barreiras (mais do que passagens), que afirmam a densidade das histórias locais (ou as singularidades regionais), mas silenciam sobre as intensas relações constituídas historicamente?

Outro desafio é o de construção de categorias que permitam não apenas a comparação, tomada a partir de nova perspectiva (construir comparáveis, diria Detienne (2004), mas que impliquem numa conceituação ou teorização na disciplina. Novos territórios epistemológicos? E isso, acreditamos, só pode ser feito pelo esforço conjugado dos vários pesquisadores (em diferentes níveis e de diferentes procedências geográficas e disciplinares). Um esforço que se expressa tanto pelo conhecimento mais detido da experiência; quanto pelo investimento em propor sínteses, sempre provisórias, ou em testar hipóteses na elaboração de quadros teóricos passíveis constantemente de revisão.

Existem alguns temas que reivindicam atenção, pois, ainda, não foram tratados por esse grupo de pesquisadores, e que dizem respeito à história da educação dos afrodescendentes e índios, assim como de minoria étnicas, como os ciganos, menonitas ${ }^{10}$, mulçumanos e judeus, dentre outras; das escritas ordinárias; do ensino de história da educação nos cursos de formação superior; do ensino especial etc.

E, aqui, parece-nos, surgir mais um desafio: religar, em novas bases, os níveis micro e macro das análises: por um lado, percebendo a diversidade do local; por outro reconhecendo sendas que nos permitem referir a um plano nacional. O exercício não é simples. Supõe que estreitemos cada vez mais os laços que unem os investigadores e os interesses de pesquisa das várias regiões/ localidades/estados, superando os entraves físicos, do deslocamento geográfico; afetivos, do apego às singularidades locais e aos objetos de investigação; e epistemológicos, da adesão estrita a paradigmas.

Por fim, resta uma palavra de reconhecimento a todos que de maneira direta ou indireta contribuíram para a concretização e consolidação desse projeto. Ao longo desse primeiro decênio, graças à persistência e ao engajamento de alunos e professores, é possível, hoje, esse grupo ser identificado como um dos núcleos de produção na área da História da Educação de maior envergadura do Estado do Paraná com significativo reconhecimento nacional, responsável pela formação de inúmeros mestres e, também, doutores, para atuarem em campos profissionais identificados com os afazeres da pesquisa

10 Atualmente a mestranda Francielly Giachini Barbosa desenvolve pesquisa de mestrado intitulada: Entre a tradição e o futuro: os menonitas e sua identidade. Curitiba, 1936-1956. 
científica, da docência e da administração em órgãos governamentais relacionados à Educação.

\section{REFERÊNCIAS}

ALVES, C. C. Os resumos das comunicações e as possibilidades esboçadas no II Congresso Luso-Brasileiro de História da Educação. In: CATANI, D.; SOUZA, C. P. (Orgs.). Práticas educativas, culturas escolares, profissão docente. São Paulo: Escrituras, 1998.

ARAUJO, M. M. O cultivo de uma historiografia engajada com a história e a memória da educação brasileira. In: ARAUJO, M. M.; XAVIER, L.; CARVALHO, M. M. C. et al. Intelectuais, Estado e Educação, vol. 2. Natal: EdUFRN, 2006. p. 185-196.

BASTOS, M. H. C. A pesquisa em História da Educação em revista. In: SCHELBAUER, A.; LOMBARDI, J.C.; MACHADO, M.C. Educação em debate. Campinas: Autores Associados, 2006. p. 99-128.

BONTEMPI JR., B. História da Educação Brasileira: o terreno do consenso. Dissertação (Mestrado em Educação) - Pontifícia Universidade Católica de São Paulo, PUC/SP, 1995.

BARREIRA, L. C. História e historiografia. As escritas recentes da história da educação brasileira (1971-1988). Tese (Doutorado em Educação) - Faculdade de Educação, Unicamp, Campinas, 1995.

BRANDÃO, Z. A Intelligentsia Educacional: um percurso com Paschoal Lemme por entre as memórias e as histórias da escola nova no Brasil. Tese (Doutorado em Educação) - Pontifícia Universidade Católica do Rio de Janeiro, PUC/RJ, 1992.

CARVALHO, M. M. C. "L'histoire de l'éducation au Brésil: traditions historiographiques et processus de rénovation de la discipline". Paedagogica Historica - Internacional; Journal of the History of Education, v. 36, n. 3, p. 909-933, 2000. 
. A configuração da historiografia educacional brasileira. In: FREITAS, M. C. (Org.). Historiografia brasileira em perspectiva. São Paulo: Contexto; Bragança Paulista: EDUSF, 1998. p. 329-353.

. O GT História da Educação: um breve histórico. In: ANPEd. Histórico dos Grupos de Trabalho, Belo Horizonte, 1995, p. 53-56.

. O novo, o velho, o perigoso: relendo a cultura brasileira. Cadernos de Pesquisa, n. 71, p. 29-35, nov. 1989.

CATANI, D. B.; SOUSA, C. P. A geração de instrumentos em pesquisa histórica da educação: estudos de revistas de ensino. In: VIDAL, D. G.; HILSDORF, M. L. S. Tópicas em História da Educação. São Paulo: Edusp, 2001. p. 241-254.

CATANI, D. B.; FARIA FILHO, L. M. Um lugar de produção e a produção de um lugar: a história e a historiografia divulgadas no GT História da Educação da ANPEd (1985-2000). Revista Brasileira de Educação, n. 19, p. 113-128, jan./abr. 2002.

DETIENNE, M. Comparar o incomparável. Aparecida: Idéias \& letras, 2004.

SAVIANI, D. Escola e Democracia. São Paulo: Cortez, 1983. (Coleção Polêmicas do nosso tempo, n. 5).

. Ensino, pesquisa e organização na formação do campo da História da Educação brasileira. In: MONARCHA, C. (Org.) História da educação brasileira: formação do campo. Ijui: UNIJUI, 2005. p. 47-116.

FREITAS, A. G. B.; ARAUJO, J. C. S.; LOPES, A. P. C. (Orgs.). As escolas normais do Brasil - do Império à República. Campinas: Editora Alínea, 2008.

GONDRA, J. G. (Org.). Pesquisa em História da Educação no Brasil. Rio de Janeiro: DP\&A Editora, 2005.

MONARCHA, C. História da educação (brasileira): formação do campo, tendências e vertentes investigativas. História da Educação (UFPel), v. 11, p. 51-78, 2007.

. História da Educação Brasileira: atos de fundação. Horizontes, Bragança Paulista/SP, n. 3, p. 35-43, 1996. 
. Notas sobre história da educação brasileira. Pro-Posições (Unicamp), Campinas/SP, v. 4, n. 3, p. 59-63, 1993.

NUNES, C. I Congresso Luso-Brasileiro de História da Educação - Leitura e Escrita em Portugal e no Brasil (1500-1970). In: FARIA FILHO, L. M. (Org.). Modos de ler e formas de escrever. Belo Horizonte: Autêntica, 1998. p. 11-28.

. Uma história em construção. In: ANPED. Documento de discussão de balanço de gestão. 1991. (mimeo).

- A instrução pública e a primeira história sistematizada da educação brasileira. Cadernos de Pesquisa, n. 93, p. 51-59, maio 1995.

. Ensino e historiografia da educação: problematização de uma hipótese. Revista Brasileira de Educação, n. 1, p. 67-79, jan./abr. 1996.

NUNES, C. I.; CARVALHO, M. M. C. Historiografia da educação e fontes. Cadernos ANPED, n. 5, set. 1993, p. 7-64.

OLIVEIRA, M. A. T. A Revista Brasileira de Educação Física e Desportos e a experiência cotidiana de professores da Rede Municipal de Ensino de Curitiba: entre a adesão e a resistência. Tese (Doutorado em Educação) - Pontifícia Universidade Católica de São Paulo, São Paulo, 2001.

SANFELICE, J. L. Perspectivas atuais da História da Educação. In: SCHELBAUER, A.; LOMBARDI, J.C.; MACHADO, M.C. Educação em debate. Campinas: Autores Associados, 2006., p. 23-52.

SAVIANI, D.; LOMBARDI, J. C.; SANFELICE, J. L. (Orgs.). História e história da educação: o debate teórico-metodológico atual. Campinas: Autores Associados/HISTEDBR, 1998.

SAVIANI, D.; LOMBARDI, J. C. Grupo de Estudos e Pesquisas História, Sociedade e Educação no Brasil (HISTEDBR): histórico e situação atual. Educação em Revista, n. 34, p. 135-146, dez. 2001.

VEIGA, C. G. Etnicidade e História da Educação. In: MORAIS, Christianni Cardoso; PORTES, Écio Antonio; ARRUDA; Maria Aparecida (Orgs.). História da Educação: ensino e pesquisa. Belo Horizonte: Autêntica, 2006, p. 27-58.

VEIGA, C. G.; PINTASSILGO, J. Pesquisas em história da educação no Brasil e em Portugal: caminhos da polifonia. Belo Horizonte/Lisboa, 2000, 17 p. Impresso. 
VIDAL, D. G. (Org.). Grupos escolares, cultura escolar primária da infância no Brasil (1893-1971). Campinas: Mercado de Letras, 2006.

VIDAL, D. G. ; FARIA FILHO, L. M. História da Educação no Brasil: a constituição histórica do campo (1880-1970). Revista Brasileira de História, v. 23, n. 45 , p. 37-70, 2003.

WARDE, M. J. Anotações para uma Historiografia da Educação Brasileira. Em Aberto, ano III, n. 23, set./out. 1984, p. 1-6.

. Contribuição da História para a Educação. Em aberto, ano IX, n. 47, jul./set. 1990, p. 3-11.

- Questões teóricas e de método: a história da educação nos marcos de uma história das disciplinas. In: SAVIANI, D. et al. História e história da educação. O debate teórico-metodológico atual. Campinas: Autores Associados, 1998. p. 88-99.

XAVIER, L. N. Particularidades de um campo disciplinar em consolidação: balanço do I Congresso Brasileiro de História da Educação (RJ/2000). In: SOCIEDADE BRASILEIRA DE HISTÓRIA DA EDUCAÇÃO (Org.). Educação no Brasil. Campinas: SBHE \& Autores Associados, 2001.

Texto recebido em 5 de fevereiro de 2009.

Texto aprovado em 8 de março de 2009. 